\title{
The Resourceful Patient 2002
}

\section{Derek Richards \\ Director, Centre for Evidence- based Dentistry}

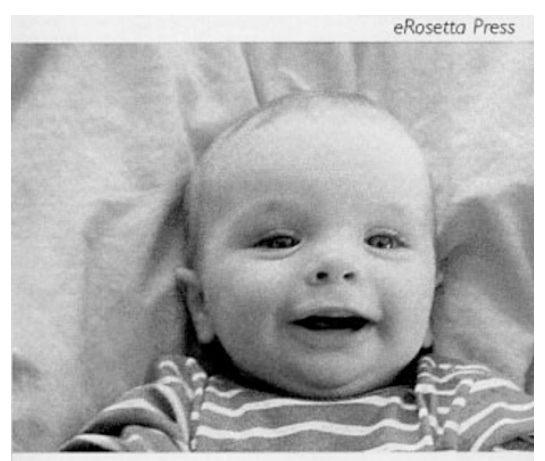

The Resourceful Patient

J A Muir Gray

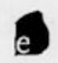

Muir Gray JA. Oxford: Rosetta Press. ISBN 1-904202-00-4

Evidence-Based Dentistry (2002) 3, 84. doi:10.1038/sj.ebd.6400132
$\mathrm{T}$ his very interesting book - or should one call it a project? - is available in 3 formats:

- as a paper book, printed on demand one copy at a time in response to each order

- as a web-site (http://www.resourcefulpatient.org/) which allows you to follow the links underlined in the book

- as an eBook

Essentially it is an electronic book that has been designed not only to be read in a linear fashion but also, if desired, to be printed out as a book with an accompanying web-site. The web-site contains a range of additional information with links from the text to other sites and material, which expands both the interest of the book and its content.

The book has four sections: the rise and fall of medical power; how doctors and patients behave; the resources patients need; and the transformation that clinicians, health services and patients need to make. It provides a fair overview of the rise and fall of medical power, describing how doctors and patients behave, particularly in consultation and diagnosis. Some may argue that these sections are superficial but the web links provided do help, although not all of them were active when I visited the site (13-14th July). Despite the usefulness of the links in the electronic format they take some getting used to in the printed version because they are underlined, which some readers may find this distracting at first.
The final two sections of the book (the resources patients need and the transformation that clinicians, health services and patients need to make) are more challenging to current practice and may indeed be a recipe for revolution, as noted on the back cover! As is clearly presented in the text, however, the ideas are merely logical extensions of work that is currently underway. Some examples are the teaching of consulting skills to patients, patients as holders of their records, and a 'patient-owned web record'. Other ideas include people arranging their own pre-operative work-up and preconsultation preparation, plus postconsultation homework for patients - with increased power comes responsibility. The potential of this "new model" of health care increasing rather than decreasing the health-care divide is noted by the author: time will tell whether we are willing or able to use these new approaches to reduce the divide.

The book is a clear and well-argued evidence-based justification for moving to this new paradigm for health care in the near future. The fact that it is heavily reliant on medical examples should not deter dentists from reading it. Practitioners will gain much from it in terms of how consultations take place now and will take place in the future. It will be useful in their day-to-day practice and even during consultations with your own doctor. Dentists, being at the upper end of educational attainment, can (or should be) resourceful patients. They should also help their own patients become resourceful. 